\title{
EXPERIMENTAL INVESTIGATION, ANN MODELLING AND TOPSIS OPTIMIZATION OF A GASOLINE PREMIXED HCCI-DI ENGINE WITH DIRECT INJECTION OF $\mathrm{FeCl}_{3}$ NANOADDITIVE BLENDED WCO
}

\begin{abstract}
Summary
Experiments have been carried out to compute performance, combustion and emission characteristics of a homogeneous charge compression ignition - direct injection (HCCI-DI) engine in which $20 \%$ of the fuel was premixed in the intake manifold and the remaining $80 \%$ of the fuel was injected directly. Gasoline was selected as the premixed fuel and three different fuel combinations, namely, diesel, B50 (50\% waste cooking oil (WCO) and 50\% diesel by volume) and WCO were selected as direct injection (DI) fuels. $100 \mathrm{ppm}$ of $\mathrm{FeCl}_{3}$ nanoadditive was blended with the DI fuels aimed at enhancing favourable fuel properties. The experimental investigations show a reduction of $54.17 \%$ and $50 \%$ in hydrocarbon (HC) and carbon monoxide (CO) emissions, respectively, in the case of WCO fuelled DI combustion compared with the diesel fuelled combustion. Significant increase in the cylinder pressure $\left(p_{\text {cyl }}\right)$ and the rate of heat release (ROHR) values was observed when the $\mathrm{FeCl}_{3}$ nanoadditive blended fuel was used. Also, with this type of fuel smoke emissions were reduced by $34.8 \%$. Significant increase in the brake thermal efficiency $\left(\eta_{\text {bth }}\right)$ with reduced nitrogen oxide $\left(\mathrm{NO}_{\mathrm{x}}\right)$ emissions was observed in the HCCI-DI combustion. Artificial neural network (ANN) was used for forecasting the performance of and emissions from the engine in different operating conditions. The technique for order preference by similarity to ideal solution (TOPSIS) was used for optimizing engine input parameters, which can result in maximum efficiency and minimum emissions.
\end{abstract}

Key words: artificial neural network, TOPSIS, HCCI-DI, $\mathrm{FeCl}_{3}$ nanoadditive, waste cooking oil

\section{Introduction}

The increase in population, rapid growth of industrialisation and the rising living standards have increased the importance and use of internal combustion (IC) engines. During combustion, a considerable amount of pollutant emissions such as carbon monoxide (CO), hydrocarbon $(\mathrm{HC})$, oxides of nitrogen $\left(\mathrm{NO}_{\mathrm{x}}\right)$ and smoke are emitted from the engine [1]. In addition, the world is facing the real possibility of fossil fuel depletion in the near future. The increased fuel demand and the introduction of stringent emission standards have led to a search for an improved combustion methodology which uses an alternative fuel. 


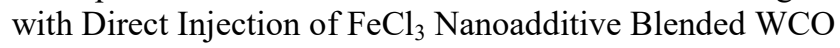

Among many alternative fuels, waste cooking oil (WCO) has been considered as a suitable alternative to fossil fuels due to its abundant and continuous availability. Also, the use of WCO as fuel in IC engines can solve the problem of disposing used cooking oil [2]. The re-use of WCO for cooking may pose potential health risks which include acidity, heart disease, Parkinson's disease, irritable throat and cancer. The used oil disposed in water may form a coating on the water surface which prevents oxygen $\left(\mathrm{O}_{2}\right)$ exchange between water and atmosphere. Further, the oil coating on the surface of the water prevents the penetration of sun rays to plants living in the water and increases organic pollution [3]. $\mathrm{HC}$ and $\mathrm{CO}$ emissions from WCO fuelled combustion engines are low. However, the use of WCO as IC engine fuel may cause higher $\mathrm{NO}_{x}$ emissions and deliver low brake thermal efficiency $\left(\eta_{\mathrm{bth}}\right)$ [4]-[6].

Homogeneous charge compression ignition (HCCI) engine is considered as a suitable engine which can reduce the $\mathrm{NO}_{\mathrm{x}}$ formation without affecting $\eta_{\mathrm{bth}}$. In 1979, Onishi et al. introduced a concept of HCCI through the process named active thermo-atmosphere combustion (ATAC) [7]. In the HCCI method, fuel is admitted into the intake manifold for the homogeneous charge to be prepared and it is then compressed during the compression stroke. Towards the end of compression, the self-ignition of the fuel initiates combustion. Therefore, combustion occurs in the entire combustion chamber, ensuing the rapid rate of heat release (ROHR). The homogeneity of the air-fuel mixture decreases particulate matter emissions. Also, HCCI combustion delivers a higher $\eta_{\text {bth }}$ due to the high compression ratio with no throttling losses [8]. HCCI is characterised by the self-ignition of the homogeneous mixture. These phenomena lead to the use of a diluted mixture and this results in a low temperature combustion. Low temperature combustion from an HCCI engine effectively reduces the $\mathrm{NO}_{\mathrm{x}}$ formation.

In the HCCI engine, the start of combustion (SOC) is governed by air-fuel interaction and fuel oxidation reaction kinetics [9]. This limits the operation of the HCCI engine in terms of the limited speed and load. The HCCI-DI engine was introduced to overcome this limitation. In the HCCI-DI engine, some proportion of the fuel is mixed with air in the intake manifold, like HCCI engine, and the remaining fuel is injected into the combustion chamber, e.g. like DI engine. The HCCI-DI engine can deliver high performance combustion and low $\mathrm{NO}_{\mathrm{x}}$ emissions [10], [11]. However, $\mathrm{HC}$ and $\mathrm{CO}$ emissions could increase because of the low temperature lean combustion.

Some researchers proposed a treatment with nanoadditives to improve the engine performance. Recently, nanoadditives such as aluminum oxide $\left(\mathrm{Al}_{2} \mathrm{O}_{3}\right)$, titanium dioxide $\left(\mathrm{TiO}_{2}\right)$, cerium oxide $\left(\mathrm{CeO}_{2}\right)$, ferric chloride $\left(\mathrm{FeCl}_{3}\right)$, cobalt oxide $\left(\mathrm{CO}_{3} \mathrm{O}_{4}\right)$, carbon nanotube $(\mathrm{CNT})$ and zirconium oxide $\left(\mathrm{ZrO}_{2}\right)$ have been analyzed for use with diesel and biodiesel [12][16].

With the introduction of high-speed computational facilities, artificial neural network (ANN) has widely been used as a forecasting tool for estimating the IC engine performance and emissions. Some researchers proposed an ANN for forecasting the characteristics of the engine, and reported that ANN results are very accurate with acceptable limits of errors [17]-[19]. It is a complicated and dynamic process to find an optimum solution to a multi-objective problem. Different approaches are available for finding the optimum solution such as the revised analytic hierarchy process (RAHP) technique, the weighted sum method (WSM), the VIKOR ranking method, the weighted product method (WPM), the technique for order preference by similarity to ideal solution (TOPSIS) and the analytic hierarchy process (AHP) technique [20].

In this study, experiments were performed to compute combustion, performance and emission characteristics of an HCCI-DI engine running on $20 \%$ of the gasoline premixed in the intake manifold and the remaining $80 \%$ of the fuel injected directly into the combustion chamber. Diesel, B50 and WCO were used as DI fuels. To analyse the influence of the $\mathrm{FeCl}_{3}$ 
nanoadditive, $100 \mathrm{ppm}$ of this nanoadditive was blended with DI fuels. Combustion, performance and emission tendency of the engine were investigated, and the outcomes were compared with the conventional diesel combustion engine. An ANN modelling tool was used to predict the engine output parameters. The values forecasted by the ANN model were compared with the experimental values. Further, the TOPSIS optimization approach was used to find the optimum input parameters so as to deliver high $\eta_{\text {bth }}$ with low exhaust emissions.

\section{Fuel preparation}

A larger molecular mass of the WCO causes an increase in the viscosity of the fuel. High viscous WCO leads to a large droplet size, poorer vaporization and narrower spray angle. Many chemical pre-treatment processes have been recommended by previous researchers for reducing the viscosity of the WCO, among which the transesterification process is well-known and commonly used.

In the transesterification process, a $100 \mathrm{ml}$ Erlenmeyer flask equipped with an external beaker and heating magnetic stirrer arrangement was used. During the transesterification, copper doped zinc oxide (CZO) nanocomposite was prepared and utilized as a heterogeneous catalytic agent while methanol was chosen as the acyl acceptor [21]. The reaction mixture was prepared by combining $\mathrm{WCO}$ heated at $50^{\circ} \mathrm{C}$, methanol and $\mathrm{CZO}$. In order to blend the reaction mixture well, a magnetic stirrer was used. The methanol to oil ratio was maintained in the range from 1.3 to 1.9 (volume of methanol/volume of WCO) and the catalytic agent concentration ranged from $2 \%$ to $14 \%$ (weight of catalytic agent/volume of WCO). This experimental setup was maintained at $35^{\circ} \mathrm{C}$ to $60^{\circ} \mathrm{C}$ for a reaction period of $70 \mathrm{~min}$. The reaction mixture was permitted to settle after the completion of the reaction period and the lower catalyst layer (solid) was removed. A separating funnel was used to separate biodiesel and glycerol. $100 \mathrm{ppm}$ of the $\mathrm{FeCl}_{3}$ nanoadditive was added to the fuel to improve physical and chemical characteristics of the fuel. In order to prepare the WCO-diesel-nanoadditive blend, an ultrasonic blender was used. The properties of the biodiesel blends are given in Table 1.

Table 1 Fuel properties

\begin{tabular}{|l|c|c|c|c|c|c|c|}
\hline & Gasoline & Diesel & B50 & WCO & $\begin{array}{c}\text { Diesel + } \\
\mathrm{FeCl}_{3}\end{array}$ & $\begin{array}{c}\mathrm{B} 50+ \\
\mathrm{FeCl}_{3}\end{array}$ & $\begin{array}{c}\mathrm{WCO}+ \\
\mathrm{FeCl}_{3}\end{array}$ \\
\hline Kinematic viscosity $\left(\mathrm{mm}^{2} / \mathrm{s}\right)$ at $40^{\circ} \mathrm{C}$ & 0.494 & 3.122 & 3.167 & 4.214 & 3.051 & 3.152 & 4.159 \\
\hline Fire point $\left({ }^{\circ} \mathrm{C}\right)$ & 62 & 73 & 82 & 194 & 71 & 79 & 189 \\
\hline Flash point $\left({ }^{\circ} \mathrm{C}\right)$ & -43 & 61.5 & 78.3 & 182 & 59 & 75.2 & 176 \\
\hline Calorific value $(\mathrm{kJ} / \mathrm{kg})$ & 45120 & 42980 & 38655 & 36540 & 43120 & 38980 & 36898 \\
\hline Density $\left(\mathrm{kg} / \mathrm{m}^{3}\right)$ at $15^{\circ} \mathrm{C}$ & 750 & 840 & 861 & 875 & 838 & 860 & 873 \\
\hline
\end{tabular}

\section{Experimental setup}

A $4.4 \mathrm{~kW}$ single cylinder diesel engine was used for carrying out the experimental investigations. Figure 1 shows the schematic presentation of the experimental setup. The selected test engine was upgraded with a supplementary fuel injection system for the preparation and supply of homogeneous fuel to the engine. This fuel injection system had four components, namely, a fuel injector, a fuel tank, a fuel pump and an electronic control unit (ECU). The fuel injector was attached to the intake manifold and a distinct fuel tank was attached for supplying the homogeneous fuel during the intake stroke. The ECU was used for controlling the quantity of fuel supplied and for the injection timing. An electric air preheater positioned upstream of the intake manifold was used for preheating the fresh air entering the engine. A closed loop controller was mounted on the electric air preheater for maintaining the 
air temperature constant at the intake manifold port. In this study, the air temperature was maintained at $60^{\circ} \mathrm{C}$. A Swingfield electrical dynamometer was connected with the engine to measure it at different engine loads.

Two thermocouples combined with a digital temperature display were connected for the purpose of measuring temperatures of inlet air and exhaust gas. An AVL GH14D/AH01 piezoelectric pressure transducer was installed for observing the cylinder pressure $\left(p_{\text {cyl }}\right)$. The pressure measurement was made with a transducer for fifty continuous cycles and average values were recorded for every experimental condition using a high-speed data acquisition system. An AVL 365C encoder was attached to the engine crank for measuring the crank angle. Emissions, such as $\mathrm{NO}_{\mathrm{x}}, \mathrm{HC}, \mathrm{CO}, \mathrm{CO}_{2}$ and $\mathrm{O}_{2}$, were measured using an AVL DI GAS 444 five gas analyzer, while an AVL 415 smoke meter was used for measuring smoke emissions.

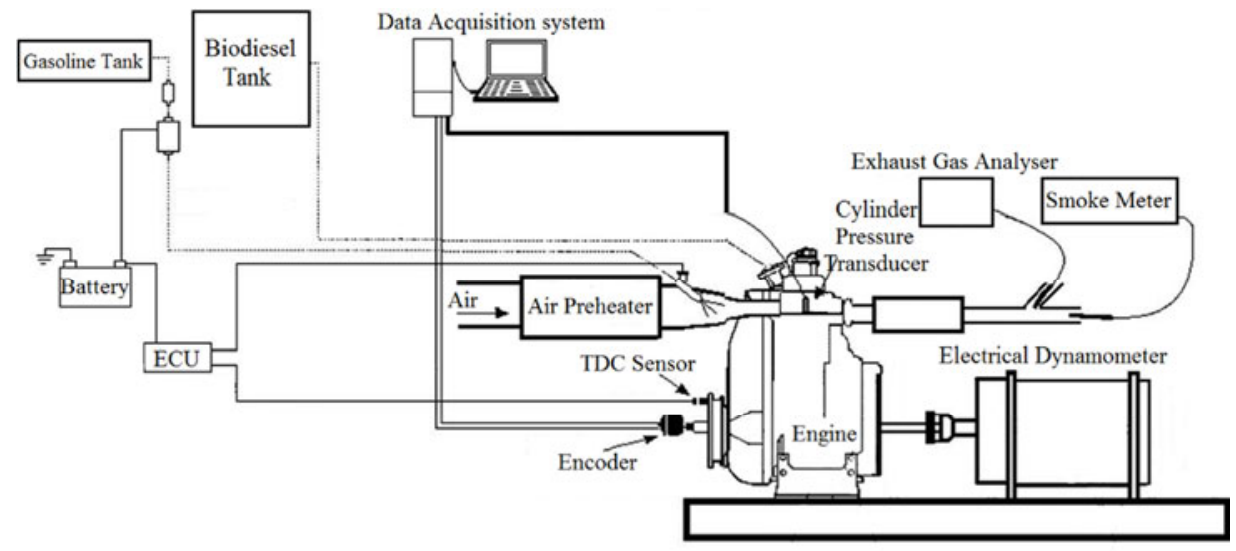

Fig. 1 Schematic diagram of the experimental setup

\section{Results and discussion}

The HCCI-DI engine was experientially examined with gasoline as the premixed fuel and different blends of WCO, diesel and B50 as the DI fuel. The effects of blending $\mathrm{FeCl}_{3}$ nanoadditives were also investigated. The results obtained from the experimental investigations on the DI and the HCCI-DI modes of operation were compared with the conventional diesel fuelled DI engine.

\subsection{Combustion characteristics}

\subsubsection{In-cylinder pressure}

In-cylinder pressure data were collected using an AVL GH14D/AH01 piezoelectric pressure transducer. The treatment of the pressure data was carried out between successive values of the raw pressure data in the form of smoothing to avoid any noisy trend in the successive pressure values. The smoothing algorithm used in this study is shown in equation (1).

$$
P_{n}=\frac{\left(P_{n-1}+2\left(P_{n}\right)+P_{n+1}\right)}{4}
$$

Figure 2 shows the comparison of $p_{\text {cyl }}$ for diesel, B50 and WCO during the DI and the HCCI-DI modes of combustion with and without the $\mathrm{FeCl}_{3}$ nanoadditive at the maximum load of the engine. The experimental investigations revealed a higher maximum $p_{\text {cyl }}\left(p_{\max }\right)$ value of diesel compared to B50 and WCO. During the DI combustion, the $p_{\max }$ values observed for diesel, B50 and WCO were 63.412 bar, 63.294 bar and 62.034 bar, respectively. This indicates that the $p_{\max }$ value of the $\mathrm{WCO}$ was $2.17 \%$ lower compared with the traditional 
diesel fuelled combustion. The reasons for the reduced $p_{\max }$ values are high viscosity, low volatility [22], early SOC, reduced micro-explosion [23] and low calorific value (CV) of the WCO [24], [25]. Low volatility and high viscosity of the WCO leads to the poor atomization of the fuel and inferior mixing of fuel with air resulting in poor burning rate and a decreased $p_{\text {max }}$. The increased portion of the WCO decreased the micro-explosion (rapid breakup of fuel droplets into tinier droplets) of the fuel which could reduce $p_{\max }$. The lower CV of the WCO reduced the heat energy released during combustion and caused a reduction in the $p_{\max }$ values. The experimental results reveal the earlier SOC when B50 and WCO are used compared with diesel, due to the availability of a higher $\mathrm{O}_{2}$ content, a relatively higher cetane number and higher density, viscosity and bulk modulus of the WCO compared with diesel. The early SOC results in less fuel accumulation during the premixed combustion phase which could be the reason for the lower $p_{\max }$ observed in the WCO fuelled combustion [26].

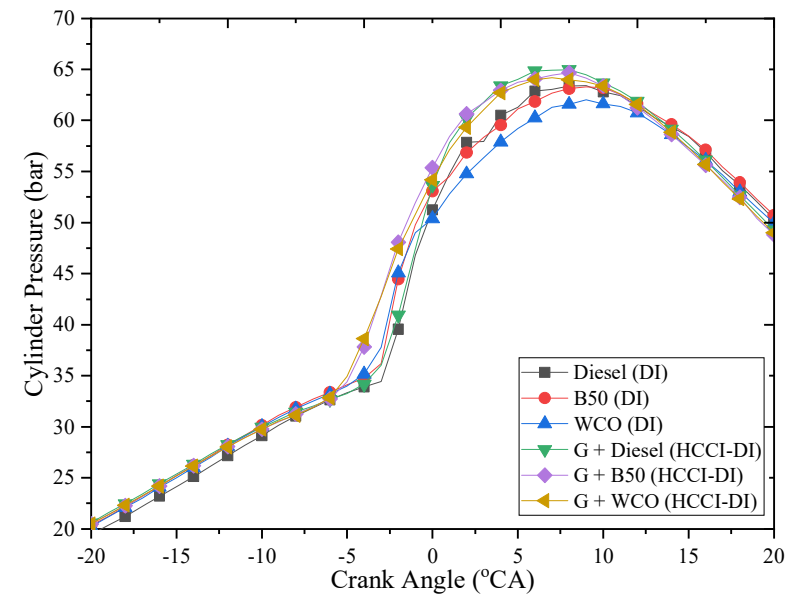

(a)

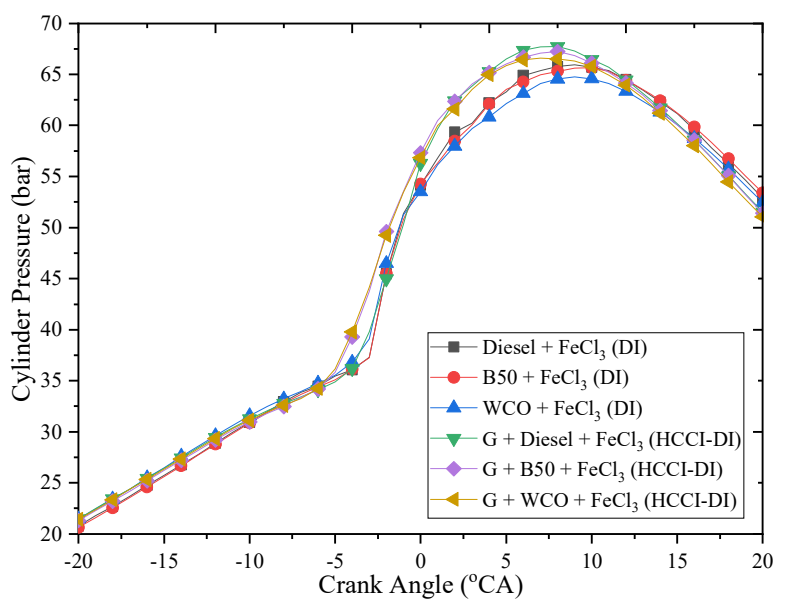

(b)

Fig. 2 Effects of DI and HCCI-DI on $p_{\text {cyl }}$ at maximum load (a) without $\mathrm{FeCl}_{3}$ additive (b) with $\mathrm{FeCl}_{3}$ additive

The premixing of gasoline caused an increase in the $p_{\max }$ values of up to $2.46 \%$ compared to the DI mode of combustion. The reasons for the increased $p_{\max }$ values of the HCCI-DI combustion could be higher fuel accumulation at the time of the SOC [27] and the homogeneous premixed fuel [28]. Since $20 \%$ of the fuel was supplied as premixed, the amount of fuel available in the combustion chamber was high at the time of the SOC. This phenomenon could increase the dominance of the uncontrolled combustion phase which could result in the high $p_{\text {cyl }}$ value.

During the DI combustion, the $p_{\max }$ values of the $\mathrm{FeCl}_{3}$ nanoadditive blended diesel, B50 and WCO were 65.926 bar, 65.642 bar and 64.767 bar, respectively. These values show a significant increase in the $p_{\max }$ values compared to neat fuel. During the gasoline premixed HCCI-DI combustion, at maximum load of the engine, the $p_{\max }$ values of the $\mathrm{FeCl}_{3}$ nanoadditive blended diesel, B50 and WCO were 67.718 bar, 67.225 bar and 66.59 bar, respectively. This is $4.23 \%$ higher than the combustion without the $\mathrm{FeCl}_{3}$ fuel blend. The enhanced combustion process generated by the catalytic action of the $\mathrm{FeCl}_{3}$ nanoadditive may be the reason for high $p_{\text {cyl }}$ values of the $\mathrm{FeCl}_{3}$ nanoadditive blended fuel [29].

\subsubsection{Rate of heat release (ROHR)}

Figure 3 shows the effects of $\mathrm{WCO}$ and $\mathrm{FeCl}_{3}$ nanoadditive on the ROHR in the case of DI and HCCI-DI combustion. A decrease in the maximum value of the ROHR ( $\mathrm{ROHR}_{\max }$ ) was observed while the percentage of the WCO in DI and HCCI-DI engines was increased. 
During the DI combustion, the $\mathrm{ROHR}_{\max }$ values for $\mathrm{B} 50$ and $\mathrm{WCO}$ were $51.232 \mathrm{~J} /{ }^{\circ} \mathrm{CA}$ and $42.619 \mathrm{~J} /{ }^{\circ} \mathrm{CA}$, respectively, whereas for diesel it was $53.024 \mathrm{~J} /{ }^{\circ} \mathrm{CA}$. During the gasoline premixed HCCI-DI combustion, the ROHR values observed for diesel, B50 and WCO were $55.601 \mathrm{~J} /{ }^{\circ} \mathrm{CA}, 52.266 \mathrm{~J} /{ }^{\circ} \mathrm{CA}$ and $45.024 \mathrm{~J} /{ }^{\circ} \mathrm{CA}$, respectively. The early SOC causes a drop in fuel accumulation in the combustion chamber at the moment of self-ignition of the fuel, which could result in a reduction in the ROHR value in the WCO fuelled engines. Higher viscosity of the WCO biodiesel could cause inferior spray formation, relatively inferior atomisation and comparatively higher time required for mixing WCO and air compared with diesel. This results in lower ROHR values of the WCO compared with diesel. The lower CV of the WCO might cause a release of a smaller amount of fuel during the combustion which results in reduced ROHR values. While comparing the DI and the HCCI-DI modes of combustion, the HCCI-DI combustion mode resulted in a significantly higher ROHR. The experimental investigations revealed that the $\mathrm{ROHR}_{\max }$ value in the gasoline premixed HCCIDI mode of combustion was $4.86 \%$ higher compared to the DI mode of combustion.

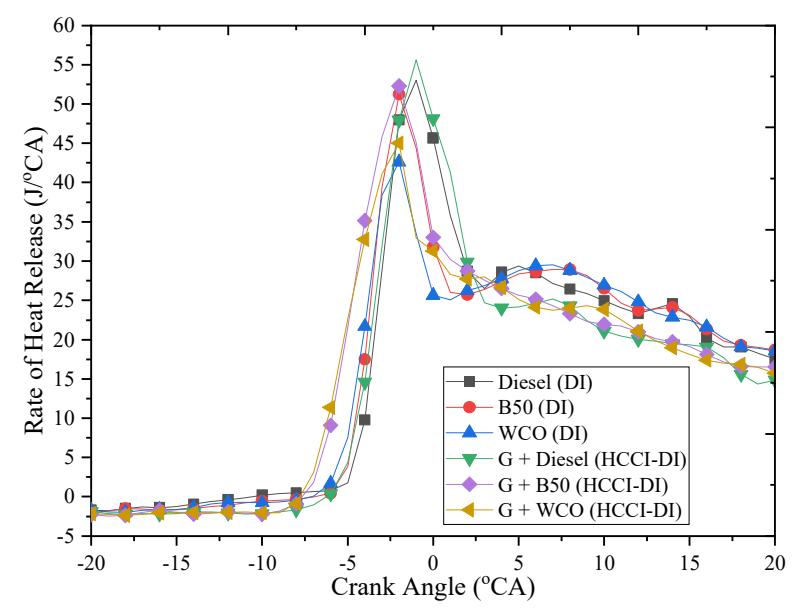

(a)

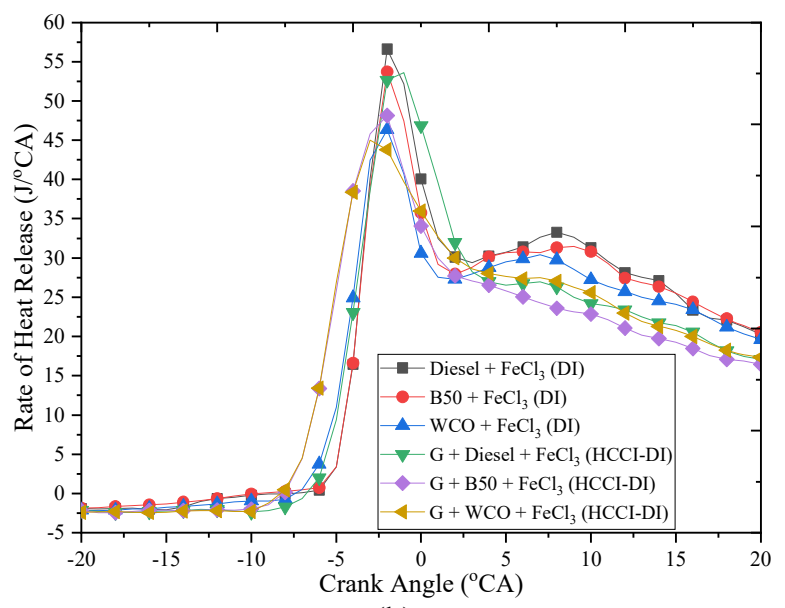

(b)

Fig. 3 Effects of DI and HCCI-DI on ROHR at maximum load (a) without $\mathrm{FeCl}_{3}$ additive

(b) with $\mathrm{FeCl}_{3}$ additive

From Figure 3, it can be inferred that the blending of the $\mathrm{FeCl}_{3}$ fuel additive resulted in a significantly higher ROHR compared to neat fuel. The catalytic reaction of the $\mathrm{FeCl}_{3}$ additive ensures better combustion resulting in an improved ROHR. The experimental results showed that the values of $56.595 \mathrm{~J} /{ }^{\circ} \mathrm{CA}, 53.733 \mathrm{~J} /{ }^{\circ} \mathrm{CA}$ and $46.350 \mathrm{~J} /{ }^{\circ} \mathrm{CA}$ were the maximum ROHR values of the $\mathrm{FeCl}_{3}$ additive blended diesel, B50 and WCO, respectively, for the DI mode of combustion at maximum engine load. This is $6.74 \%$ higher compared to the combustion with neat fuel. During the gasoline premixed HCCI-DI combustion at the maximum load of the engine, the $\mathrm{ROHR}_{\max }$ values of the $\mathrm{FeCl}_{3}$ additive blended diesel, $\mathrm{B} 50$ and $\mathrm{WCO}$ were $53.613 \mathrm{~J} /{ }^{\circ} \mathrm{CA}, 48.135 \mathrm{~J} /{ }^{\circ} \mathrm{CA}$ and $45.008 \mathrm{~J} /{ }^{\circ} \mathrm{CA}$, respectively.

\subsection{Performance characteristics}

\subsubsection{Brake thermal efficiency $\left(\eta_{\text {bth }}\right)$}

Figure 4 shows $\eta_{\text {bth }}$ of the engine operated under the DI and the HCCI-DI modes of operation in various load conditions. The observations show a decrease in $\eta_{\text {bth }}$ with an increase in the amount of the WCO. At the maximum load of the engine, during the DI combustion, the $\eta_{\text {bth }}$ values of B50 and $\mathrm{WCO}$ were $27.9 \%$ and $27.2 \%$, respectively, whereas, 
the $\eta_{\text {bth }}$ value of diesel was $28.4 \%$. During the gasoline premixed HCCI-DI operation at full load the $\eta_{\text {bth }}$ values for diesel, B50 and WCO were $29.6 \%, 28.8 \%$ and $28.1 \%$, respectively. This could be due to the high viscosity of the WCO resulting in inferior atomisation of the fuel, higher density and lower CV of the WCO leading to higher fuel supply, early SOC causing increased heat loss and poor combustion characteristics and volatility of WCO compared with the diesel fuel [30]. Generally, the fuel injections pump on the engine supplies fuel on the volume basis. As the density of the WCO blended fuel is higher than that of diesel, the fuel injection pump would release a larger volume of the WCO compared with diesel [31]. Also, the lower CV of the WCO could cause an increase in fuel supply to the engine compared with diesel to keep an equal energy input to the engine [32]. From the observations it can be concluded that the HCCI-DI mode of combustion gives a high $\eta_{\text {bth }}$ compared to the conventional DI combustion. The experimental results showed that at maximum load of the engine the $\eta_{\text {bth }}$ value for the HCCI-DI combustion was $29.6 \%$, whereas for the DI combustion it was $28.4 \%$. This could be due to the lean combustion from the HCCI-DI engine with improved conversion efficiency of the available energy in the fuel into useful work [33].

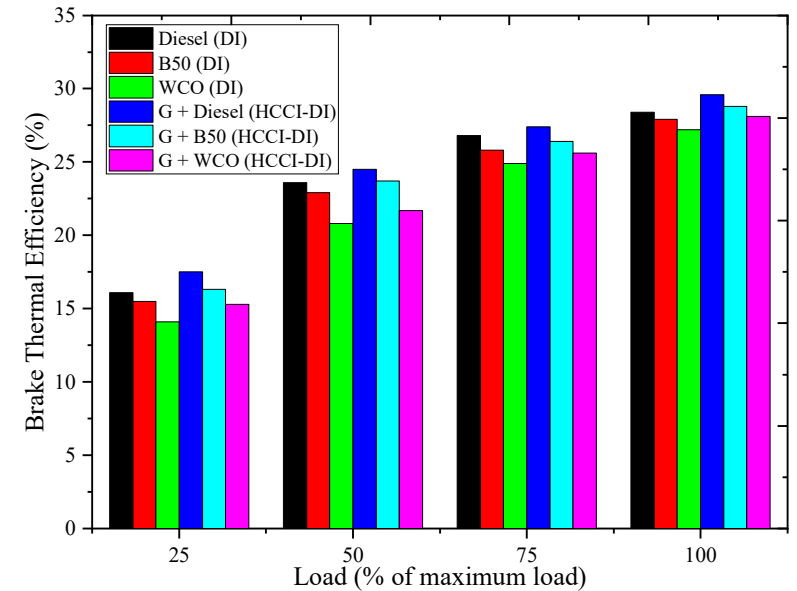

(a)

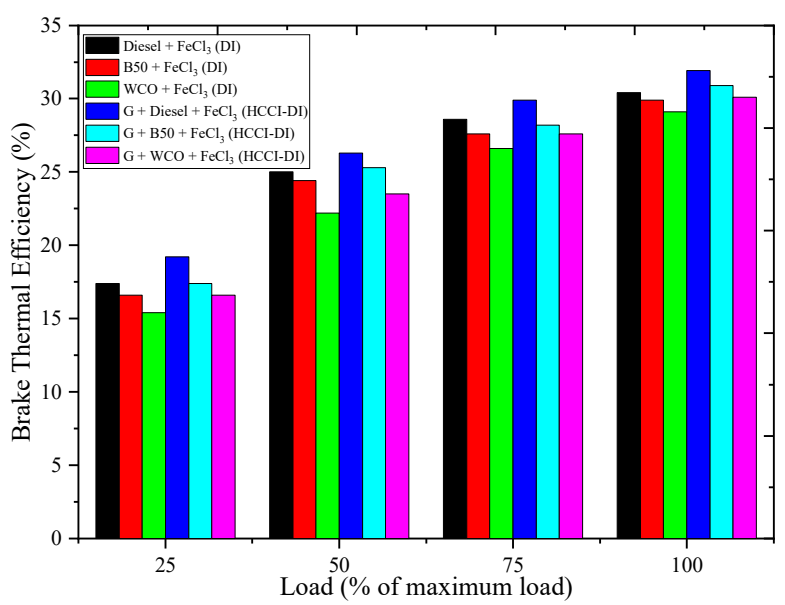

(b)

Fig. 4 Effects of DI and HCCI-DI on $\eta_{\text {bth }}$ (a) without $\mathrm{FeCl}_{3}$ additive (b) with $\mathrm{FeCl}_{3}$ additive

Figure 4 (b) shows the effects of the $\mathrm{FeCl}_{3}$ nanoadditive on $\eta_{\text {bth }}$ for the DI and the HCCI-DI combustions. During the DI mode of combustion at maximum engine load the $\eta_{\mathrm{bth}}$ values of the $\mathrm{FeCl}_{3}$ additive blended diesel, B50 and $\mathrm{WCO}$ were $30.4 \%, 29.9 \%$ and $29.1 \%$, respectively. The results indicate that the dosing of the $\mathrm{FeCl}_{3}$ additive could result in improved $\eta_{\text {bth }}$ than the neat fuel. In the HCCI-DI mode of combustion, the addition of the $\mathrm{FeCl}_{3}$ additive to the DI fuel caused an increase in the $\eta_{\text {bth }}$ value compared to the combustion without the $\mathrm{FeCl}_{3}$ additive. During the HCCI-DI mode of combustion, the $\eta_{\mathrm{bth}}$ values of the engine of the $\mathrm{FeCl}_{3}$ additive blended diesel, $\mathrm{B} 50$ and $\mathrm{WCO}$ were $31.9 \%, 30.9 \%$ and $30.1 \%$, respectively.

\subsection{Emission characteristics}

\subsubsection{Oxides of nitrogen $\left(\mathrm{NO}_{\mathrm{x}}\right)$ emissions}

Figure 5 (a) clearly illustrates that $\mathrm{NO}_{\mathrm{x}}$ emissions from the engine increase with an increase in the concentration of the WCO blended with diesel. During the conventional DI combustion at maximum engine load $6.31 \%$ and $18.32 \%$ increases in $\mathrm{NO}_{\mathrm{x}}$ emissions were noted for B50 and WCO in comparison with diesel. In the case of the HCCI-DI combustion at 
the highest load $\mathrm{B} 50$ and $\mathrm{WCO}$ emitted $7.22 \%$ and $10.15 \%$ more $\mathrm{NO}_{\mathrm{x}}$ than the DI diesel combustion. $\mathrm{NO}_{\mathrm{x}}$ emissions are higher because of a higher $\mathrm{O}_{2}$ concentration in the WCO, the presence of unsaturated fatty acid and the high cetane number. $\mathrm{O}_{2}$ in the WCO could increase the probability of complete combustion of the WCO. As a result of this, the adiabatic flame temperature could increase and hence an increase in $\mathrm{NO}_{\mathrm{x}}$ occurs. Also, $\mathrm{O}_{2}$ existing in the WCO enhances the reaction with nitrogen, which results in an increase in the $\mathrm{NO}_{\mathrm{x}}$ formation. The higher cetane number of the WCO leads to a shorter delay period. This reduces the volume of fuel in the premixed combustion, thereby allowing less time for mixing WCO and air which results in the higher $\mathrm{NO}_{\mathrm{x}}$ formation.

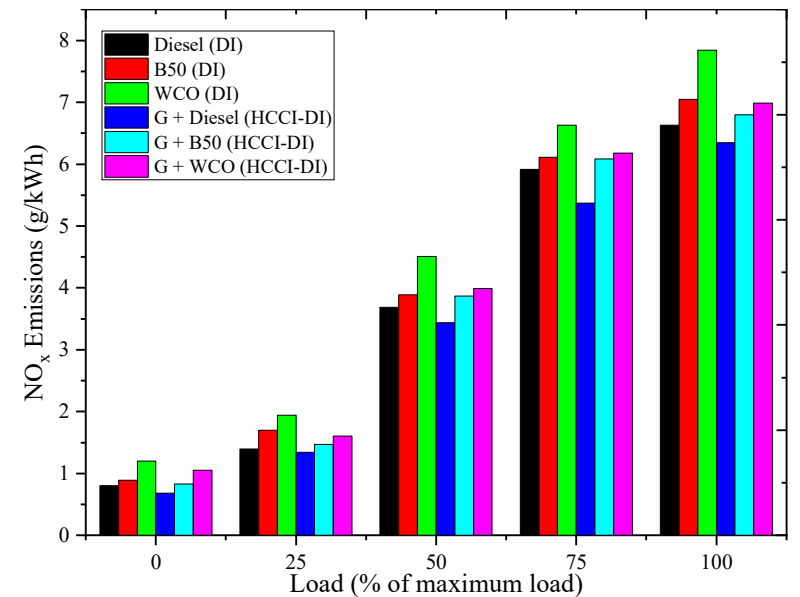

(a)

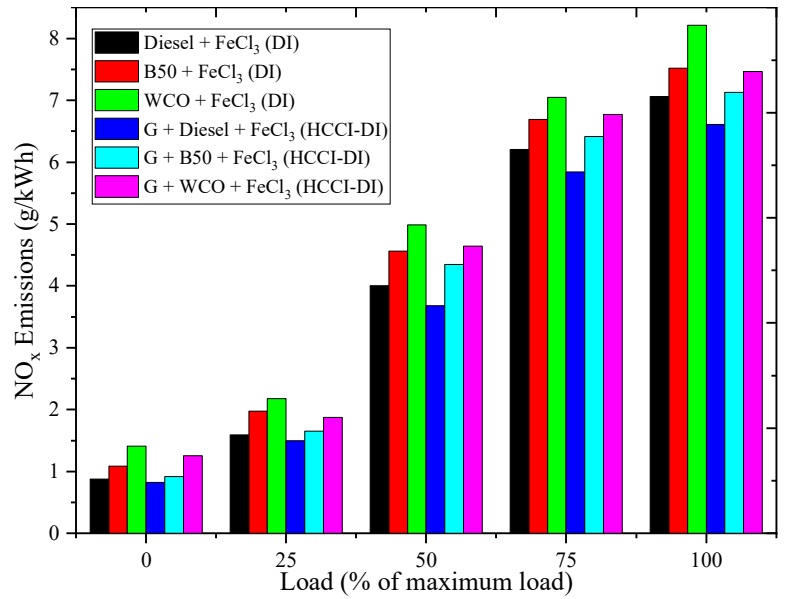

(b)

Fig. 5 Effects of DI and HCCI-DI on $\mathrm{NO}_{\mathrm{x}}$ (a) without $\mathrm{FeCl}_{3}$ additive (b) with $\mathrm{FeCl}_{3}$ additive

The experimental results showed that the HCCI-DI mode of combustion produced less $\mathrm{NO}_{\mathrm{x}}$ emissions compared to the conventional DI mode of combustion. In peak engine load operating conditions, the gasoline premixed HCCI-DI combustion emitted $4.3 \%$ less NOx than the DI combustion. This is due to the reduced flame temperature during the combustion of the lean homogeneous premixed charge. Since the formation of $\mathrm{NO}_{\mathrm{x}}$ is a function of temperature, even a small decrease in the temperature of the flames could reduce $\mathrm{NO}_{\mathrm{x}}$ emissions significantly [34].

Figure 5 (b) shows high $\mathrm{NO}_{\mathrm{x}}$ emissions for the DI and the HCCI-DI modes of operation with the $\mathrm{FeCl}_{3}$ additive blended fuel when compared to the neat fuel. For the DI mode of operation at maximum engine load the $\mathrm{NO}_{\mathrm{x}}$ emissions observed for the $\mathrm{FeCl}_{3}$ additive blended diesel, B50 and WCO were $7.06 \mathrm{~g} / \mathrm{kWh}, 7.52 \mathrm{~g} / \mathrm{kWh}$ and $8.21 \mathrm{~g} / \mathrm{kWh}$, respectively. The $\mathrm{NO}_{\mathrm{x}}$ emissions of the $\mathrm{FeCl}_{3}$ additive fuelled combustion were $6.51 \%$ higher compared to the neat fuelled combustion. During the HCCI-DI mode of combustion, the engine emitted very low $\mathrm{NO}_{\mathrm{x}}$ due to the modest combustion temperature. The experimental results showed a $6.39 \%$ decrease in $\mathrm{NO}_{\mathrm{x}}$ in the case of HCCI-DI compared with DI.

\subsubsection{Hydrocarbon (HC) emissions}

In Figure 6 (a), HC emissions show a decreasing trend with the increasing engine load. At lower loads a relatively higher ignition delay increases the expansion of the lean spray flame-out region which causes production of more $\mathrm{HC}$ emissions. Also, at lower load operations, the lean mixture may escape through the exhaust because of poor fuel distribution. The $\mathrm{HC}$ results showed that the $\mathrm{HC}$ emissions decreased while the proportion of the WCO increased. This could be due to the fact that WCO contains $\mathrm{O}_{2}$ and a shorter ignition delay. $\mathrm{O}_{2}$ 
in the WCO promotes a more complete combustion. The early SOC of the WCO could provide the time necessary for complete combustion. Under maximum load conditions in the DI combustion $29.17 \%$ and $54.17 \%$ decrease in $\mathrm{HC}$ was measured for B50 and WCO, respectively, compared with the diesel fuelled DI combustion. In the HCCI-DI engine, 9.52\% and $21.43 \%$ decrease in $\mathrm{HC}$ emissions was found for B50 and $\mathrm{WCO}$, respectively, compared with diesel.

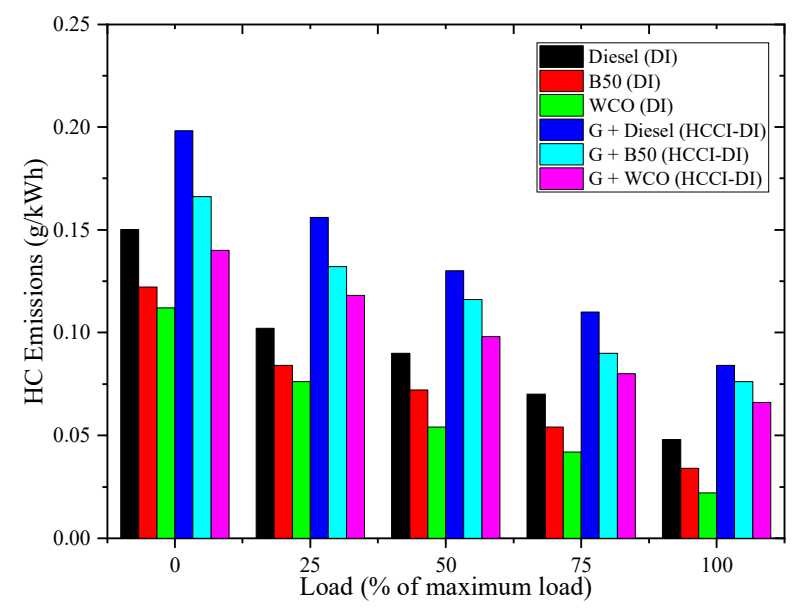

(a)

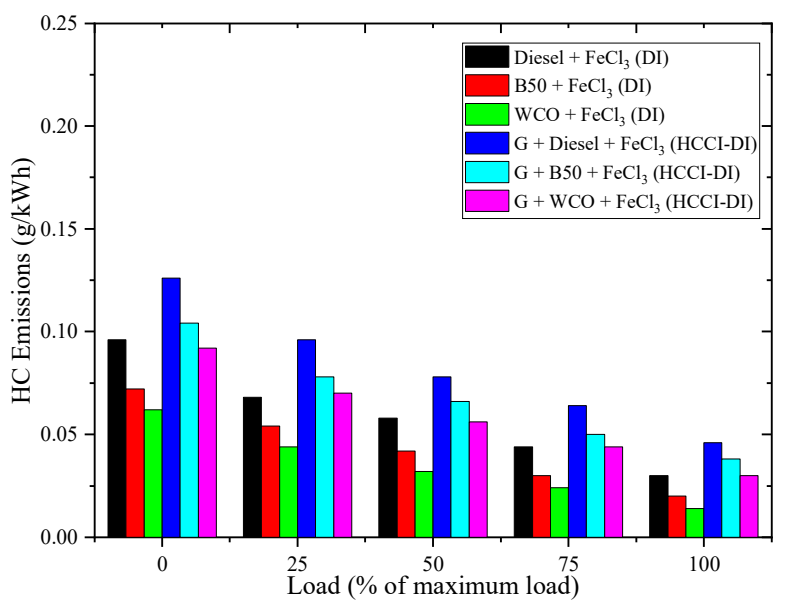

(b)

Fig. 6 Effects of DI and HCCI-DI on $\mathrm{HC}$ emissions (a) without $\mathrm{FeCl}_{3}$ additive (b) with $\mathrm{FeCl}_{3}$ additive

Figure 6 (b) shows the effects of the $\mathrm{FeCl}_{3}$ fuel additive on $\mathrm{HC}$ emissions for the DI and the HCCI-DI modes of operation. The experimental outcomes showed that the $\mathrm{FeCl}_{3}$ fuel additive blended fuel caused a reduction in $\mathrm{HC}$ emissions as the $\mathrm{FeCl}_{3}$ additive catalyzed the combustion of unburnt $\mathrm{HC}$ into $\mathrm{CO}_{2}$ and water vapour [4]. During the DI mode of operation at maximum engine load the $\mathrm{HC}$ emissions decreased up to $36 \%, 40.98 \%$ and $44.64 \%$ for the $\mathrm{FeCl}_{3}$ additive blended diesel, B50 and WCO, respectively, when compared to neat fuel. During the DI combustion, the experimental results showed a $35.42 \%$ reduction in the $\mathrm{HC}$ emissions when the $\mathrm{FeCl}_{3}$ additive blended $\mathrm{WCO}$ was used compared to the $\mathrm{FeCl}_{3}$ additive blended diesel. The experimental results revealed that the HCCI-DI mode of combustion delivered high HC emissions compared to the DI combustion. In the case of the $\mathrm{FeCl}_{3}$ blended fuel, the HCCI-DI combustion delivered $31.25 \%$ higher $\mathrm{HC}$ emissions than the DI combustion.

\subsubsection{Smoke emissions}

The variations in smoke emissions for various engine loads for the DI and the HCCI-DI combustion without the $\mathrm{FeCl}_{3}$ nanoadditive are presented in Figure 7(a). At maximum engine load the probability of the fuel rich zone formation inside the cylinder could increase. The fuel rich zones could generate solid carbon particles during combustion. Thus, the engine could emit a large amount of smoke at higher engine loads. The smoke emission results showed a decreasing trend when the proportion of the WCO was increased. The reduction in smoke emissions from WCO blends may be due to the presence of more $\mathrm{O}_{2}$ atoms in the WCO, which contribute to the improved combustion of the WCO. At maximum load during the DI combustion B50 and WCO generated $17.4 \%$ and $22.69 \%$ less smoke emissions, respectively, compared to diesel. 


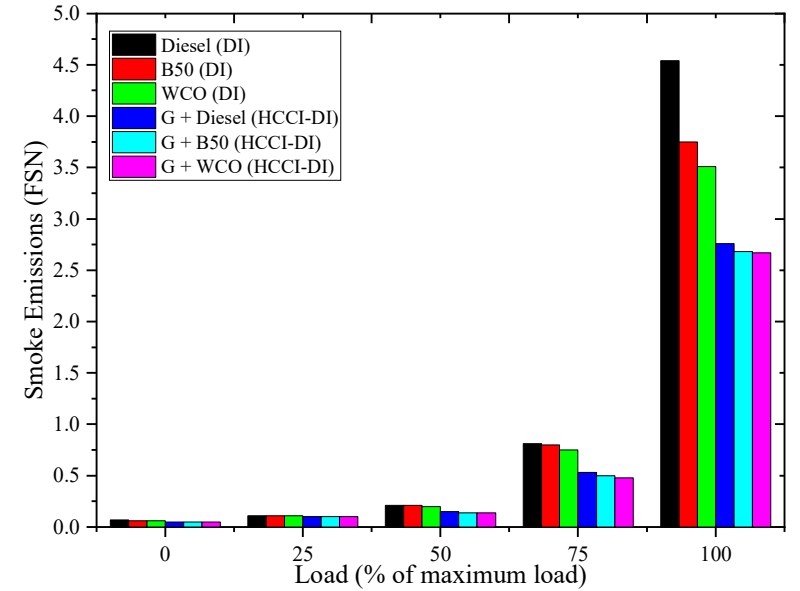

(a)

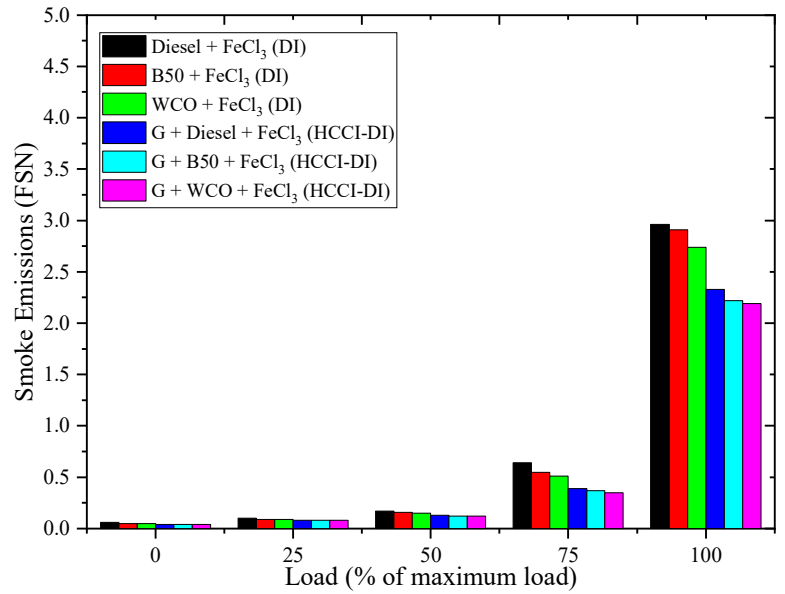

(b)

Fig. 7 Effects of DI and HCCI-DI on smoke emissions (a) without $\mathrm{FeCl}_{3}$ additive (b) with $\mathrm{FeCl}_{3}$ additive

The experimental results reveal that less smoke is emitted in the case of the HCCI-DI mode of combustion than the DI mode of combustion. Smoke is produced to a longer extent as a result of the unevenness in the air and fuel blend. The premixing of fuel in the HCCI-DI engine significantly reduces the imbalance in the air and fuel blending which results in reduced smoke emissions compared to the DI mode of operation. In the case of the HCCI-DI combustion at maximum load of the engine the premixing of gasoline produced $39.21 \%$ less smoke emissions compared to the diesel fuelled DI combustion.

Figure 7 (b) shows variations in smoke emissions between the DI and the HCCI-DI modes of operation when the $\mathrm{FeCl}_{3}$ additive is used. The experimental results revealed that the $\mathrm{FeCl}_{3}$ additive blended fuel produced less smoke emissions. During the DI combustion at maximum load of the engine the smoke emissions decreased to about $34.8 \%, 22.4 \%$ and $21.94 \%$ for the $\mathrm{FeCl}_{3}$ additive blended diesel, B50 and WCO, respectively, compared to neat diesel, B50 and WCO. The increased percentage of the WCO blend with diesel leads to decreased smoke emissions. During the DI combustion in maximum load operating conditions a $7.43 \%$ decrease was observed in smoke emissions from the $\mathrm{FeCl}_{3}$ additive blended WCO when compared with the $\mathrm{FeCl}_{3}$ additive blended diesel. For the HCCI-DI combustion at maximum load the $\mathrm{FeCl}_{3}$ additive blended diesel, B50 and $\mathrm{WCO}$ emitted 21.28\%, 23.71\% and $20.07 \%$ less smoke, respectively, compared with the DI combustion with the $\mathrm{FeCl}_{3}$ additive blended diesel, B50 and WCO.

\subsubsection{Carbon monoxide (CO) emissions}

In Figure 8, the levels of $\mathrm{CO}$ for the DI and the HCCI-DI modes of combustion with and without $\mathrm{FeCl}_{3}$ additive are shown. Emissions of $\mathrm{CO}$ are caused by an incomplete combustion due to an insufficient quantity of air in a fuel-air blend or an insufficient time for the combustion. The experimental results showed that the $\mathrm{CO}$ emissions decreased when the load on the DI and HCCI-DI engines increased. At lower engine loads, the inferior combustion temperature inside the engine may be the reason for high $\mathrm{CO}$ emissions. The experimental results showed that the $\mathrm{CO}$ emissions decreased when the quantity of the WCO was increased. In the case of the DI mode of combustion at lower engine load conditions B50 and WCO emitted low levels of CO of up to $20 \%$ and $50 \%$, respectively, compared with diesel. The decreased CO emissions in the case of the use of WCO and its blends may be due to the existence of a high volume of $\mathrm{O}_{2}$ molecules present in the fuel compared to that of 
diesel. In the case of the HCCI-DI engine at lower engine load conditions the use of B50 and WCO resulted in lower CO emissions of up to $7.14 \%$ and $35.71 \%$, respectively, compared to diesel.

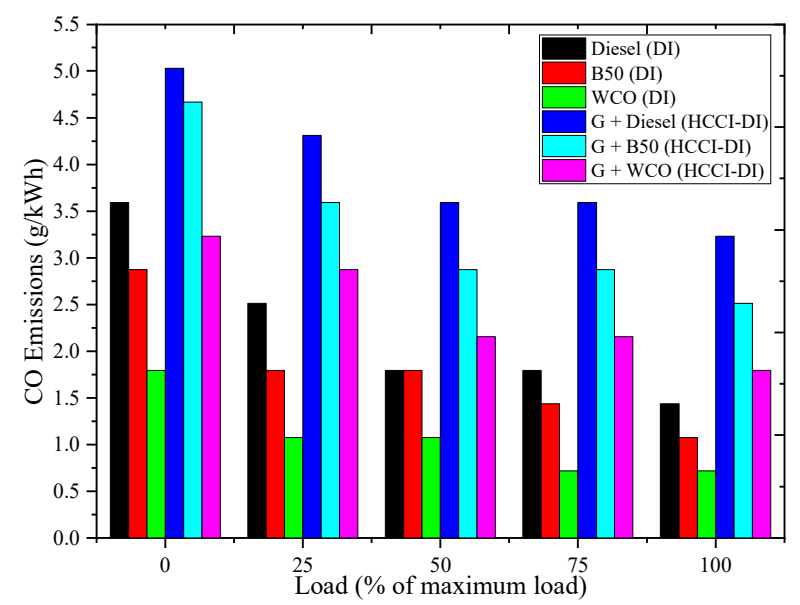

(a)

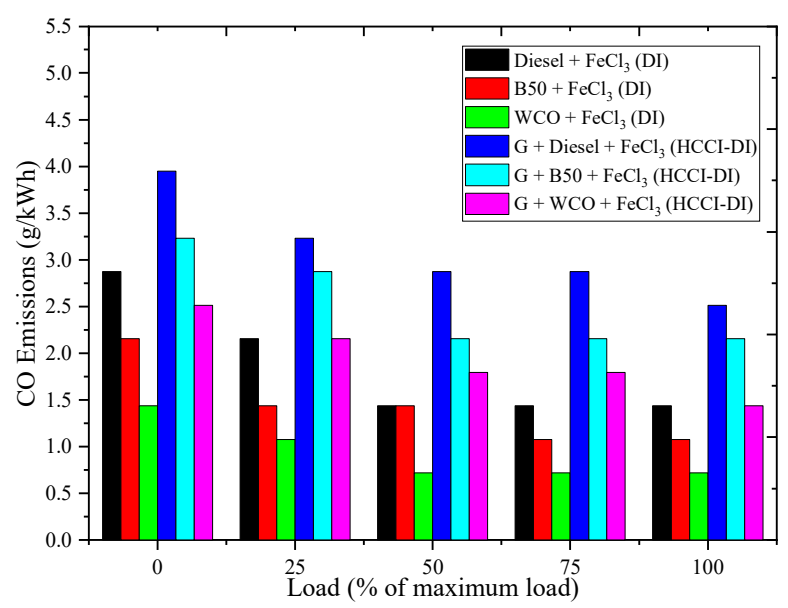

(b)

Fig. 8 Effects of DI and HCCI-DI on $\mathrm{CO}$ (a) without $\mathrm{FeCl}_{3}$ additive (b) with $\mathrm{FeCl}_{3}$ additive

The experimental observations show that the gasoline premixing in the HCCI-DI engine has caused a rise in $\mathrm{CO}$ emissions. The lower burned gas temperature in the homogeneous combustion results in an increase in $\mathrm{CO}$ emissions compared with the conventional engine. In the case of the HCCI-DI mode of combustion the premixing of gasoline results in $40 \%$ higher $\mathrm{CO}$ emissions compared to the conventional diesel fuelled DI combustion. The investigations revealed that the addition of the $\mathrm{FeCl}_{3}$ fuel additive reduced $\mathrm{CO}$ emissions. During the DI mode of combustion, the $\mathrm{FeCl}_{3}$ additive blended diesel, $\mathrm{B} 50$ and $\mathrm{WCO}$ reduced $\mathrm{CO}$ emissions by up to $20 \%, 25 \%$ and $20 \%$, respectively, compared with neat diesel, B50 and WCO.

\section{ANN Modelling}

ANN is formulated according to the arrangements and types of neurons. In this study, multi-layer perceptron (MLP) (otherwise called back propagation network) was used as the neural network. Figure 9 shows the MLP architecture used in this study. The MLP has three kinds of neurons, i.e. input neurons, output neurons and hidden neurons. The neuron configuration in this study was 4-2-5 in which four neurons will be the input layer indicating DI fuel, the percentage of gasoline premixing, the amount of $\mathrm{FeCl}_{3}$ additive and load. The two hidden layers have a number of different neurons, whereas five neurons are present in the output layer denoting $\eta_{\mathrm{bth}}, \mathrm{NO}_{\mathrm{x}}, \mathrm{HC}$, smoke and $\mathrm{CO}$.

In the selected multi-layer feed forward neural network model, a log-sigmoid activation function was used for hidden and output neurons because it has self-limiting characteristics and its outcome cannot grow extremely larger or smaller. The gradient descent rule was used in error minimization. As the mean square error (MSE) has properties such as differentiability, symmetry, convexity and an excellent metric in the context of optimization the MSE was utilized as the loss function. In the feed forward network model, a back propagation learning scheme was used with the Levenberge Marquardt learning algorithm in order to minimize the MSE. 

with Direct Injection of $\mathrm{FeCl}_{3}$ Nanoadditive Blended WCO

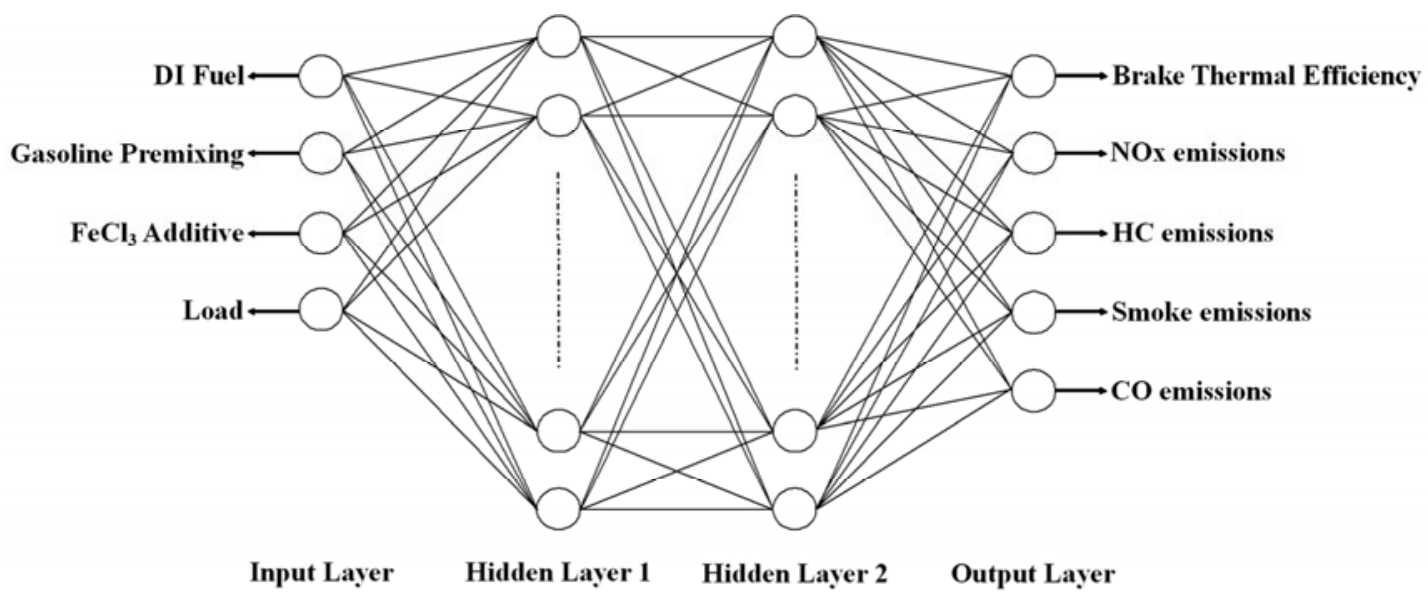

Fig. 9 MLP architecture

For increasing the model accuracy and for preventing the domination of any parameter in the output, the variables were normalized using equation (2) in the range from 0 to 1.

$$
v^{*}=\frac{\left(v-v_{\min }\right)}{\left(v_{\max }-v_{\min }\right)}
$$

where $v^{*}$ is the normalized output variable, $v$ is the non-normalized output variable and $v_{\max }$ and $v_{\min }$ are the maximum and minimum output variables. About $70 \%$ of the experimental values were used in the training process and the remaining $30 \%$ were used for testing and validation.
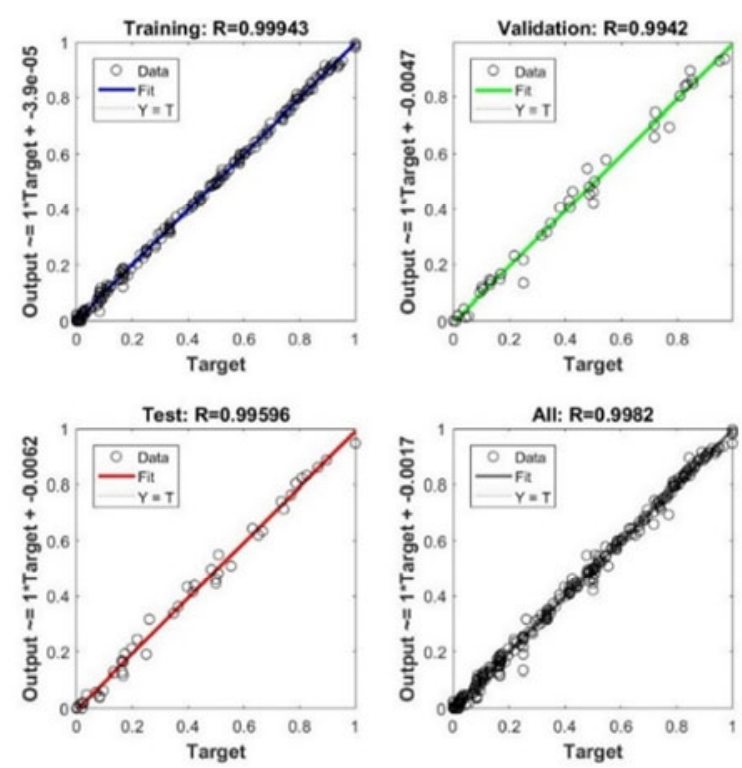

Fig. 10 Overall correlation coefficients

Figure 10 shows the correlation coefficients (R) of the suggested network architecture. It is found that the values of $\mathrm{R}$ are almost 1 in training, test and validation phases. Thus, it was concluded that the proposed ANN was able to deliver accurate simulations. Since all the values in this model were normalized, the predicted values were de-normalized using the inverse of equation (2) for obtaining the actual value.

The proposed ANN model was tested by using two statistical error methods: MAPE (Mean Absolute Percentage Error) and NRMSE (Normalized Root Mean Square Error). The error, as described by the above measures, can be defined as mentioned in equations (3) - (5).

$$
N R M S E=\frac{R S M E}{\left(t_{\max }-t_{\min }\right)}
$$


where,

$$
R M S E=\sqrt{\frac{1}{m} \sum_{i=1}^{m}\left(t_{i}-o_{i}\right)^{2}}
$$

where $m$ is the number of experiments, $t_{\mathrm{i}}$ and $o_{\mathrm{i}}$ are the experimental and the ANN predicted values at $i^{\text {th }}$ experiment, $t_{\max }$ and $t_{\min }$ are the maximum and minimum values, respectively, in the experimental outputs.

$$
M A P E=\frac{1}{m} \sum_{i=1}^{m}\left(\left|\frac{t_{i}-o_{i}}{t_{i}}\right|\right) \times 100
$$

The proposed ANN model was evaluated using $R$ and the coefficient of determination $\left(R^{2}\right) . R$ and $R^{2}$ are defined through equations (6) and (7) as follows:

$$
\begin{aligned}
& R=\sqrt{1-\frac{\sum_{i=1}^{m}\left(\left(t_{i}-o_{i}\right)^{2}\right)}{\sum_{i=1}^{m} o_{i}{ }^{2}}} \\
& R^{2}=1-\frac{\sum_{i=1}^{m}\left(\left(t_{i}-o_{i}\right)^{2}\right)}{\sum_{i=1}^{m} o_{i}{ }^{2}}
\end{aligned}
$$

Table 2 MAPE, NRMSE, $R$ and $\mathrm{R}^{2}$

\begin{tabular}{|l|c|c|c|c|}
\hline & MAPE & NRMSE & \multirow{2}{*}{$\mathrm{R}$} & \multirow{2}{*}{$\mathrm{R}^{2}$} \\
\cline { 2 - 3 } & $\%$ & $\%$ & & \\
\hline$\eta_{\text {bth }}(\%)$ & 0.407336 & 0.018273 & 0.999718 & 0.999436 \\
\hline $\mathrm{NO}_{\mathrm{x}}(\mathrm{ppm})$ & 0.008367 & 0.014461 & 0.999737 & 0.999474 \\
\hline $\mathrm{HC}(\mathrm{ppm})$ & 0.013317 & 0.019361 & 0.999155 & 0.99831 \\
\hline Smoke $(\mathrm{FSN})$ & 0.340222 & 0.013581 & 0.998994 & 0.99799 \\
\hline $\mathrm{CO}(\%)$ & 0.048373 & 0.027733 & 0.998755 & 0.997512 \\
\hline
\end{tabular}
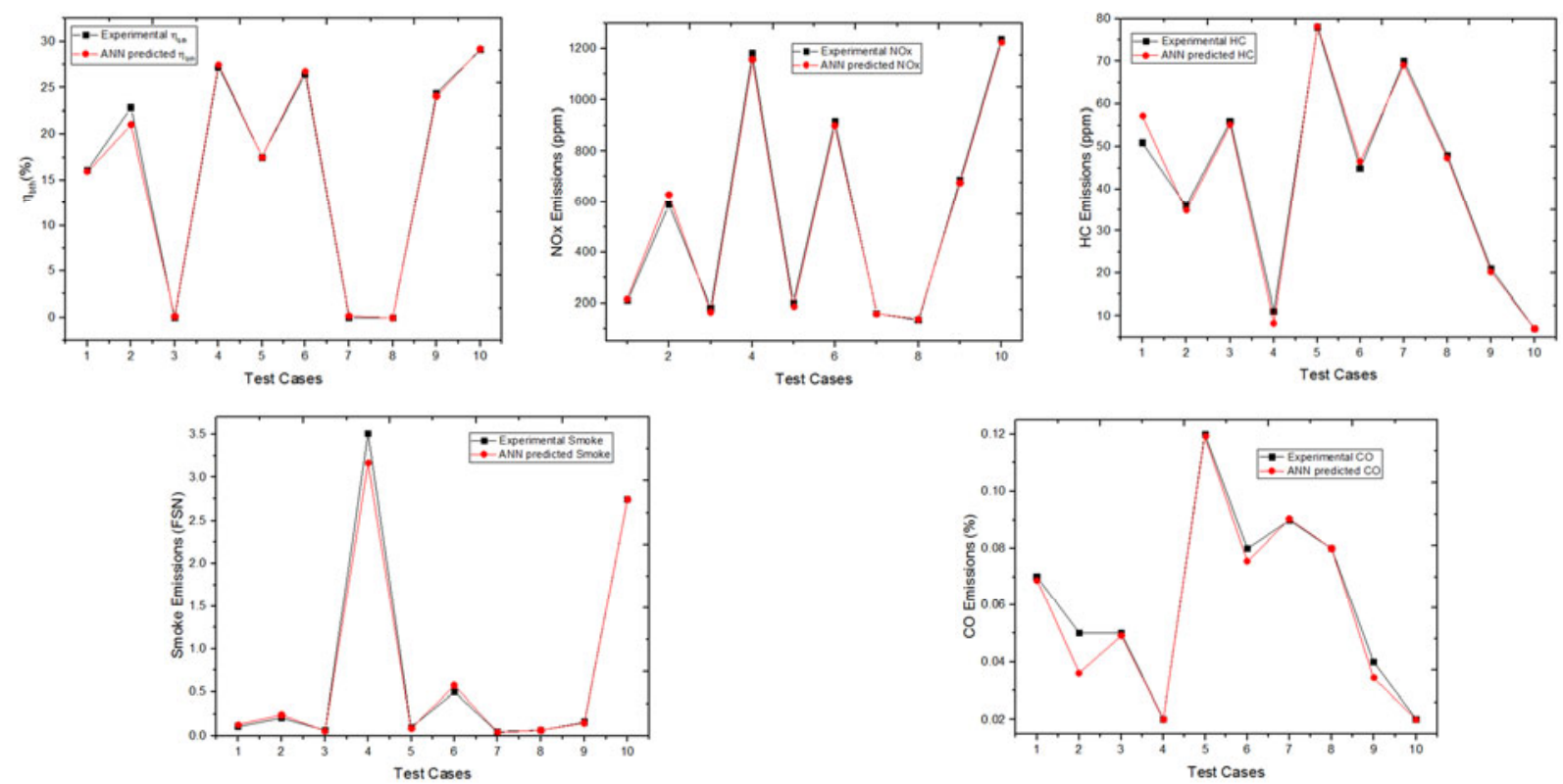

Fig. 11 Comparison of ANN predicted values and experimental outcomes

Table 2 shows NRMSE, MAPE, $R$ and $R^{2}$ values calculated by using equations (3) - (7). The maximum NRSME error value of $0.027733 \%$ was recorded for CO emissions. The maximum MAPE value was $0.340222 \%$ and it was recorded for smoke emissions. The lowest values of NRSME and MAPE indicate that the model predictions possess a high range of accuracy with acceptable error limits. $R$ and $R^{2}$ values were very close to 1 for all output 
variables. Thus, the predicted ANN model was validated, and the results showed a satisfactory level of accurateness for all ranges of the input variables.

Figure 11 compares the experimental values and the values predicted by the ANN for ten randomly selected experiments. Figure 11 clearly shows that the experimental values and the ANN predicted values are very close for all ranges of operations. The lower range of absolute error and closeness of the values from the experiment and the ANN prediction confirm that the predictions of $\eta_{\mathrm{bth}}, \mathrm{NO}_{\mathrm{x}}, \mathrm{HC}$, smoke and $\mathrm{CO}$ from the proposed ANN model have a high range of accuracy and the forecasting model can be used as a modelling tool to predict output variables for any range of operations.

\section{TOPSIS optimization}

The TOPSIS methodology deploys vector normalization to eliminate units of criterion functions. The solution retrieved from the TOPSIS method will be close to the positive ideal solution $\left(v_{\mathrm{j}}^{+}\right)$, whereas it will be far away from the negative ideal solution $\left(v_{\mathrm{j}}^{-}\right) \cdot v_{\mathrm{j}}^{+}$increases the benefit criteria and decreases the conflicting criteria, $v_{\mathrm{j}}{ }^{-}$works the opposite i.e., it increases the conflicting criteria and decreases the benefit criteria. The TOPSIS values are calculated using the steps given below.

Step 1: Construction of a decision making (DM) matrix

The TOPSIS method begins with the construction of a DM matrix.

$$
D M=\left[\begin{array}{c}
A_{1} \\
A_{2} \\
\vdots \\
A_{m}
\end{array}\right]\left[\begin{array}{cccc}
Z_{11} & z_{12} & \cdots & z_{1 n} \\
z_{21} & Z_{22} & \cdots & z_{2 n} \\
\vdots & \vdots & \cdots & \vdots \\
z_{m 1} & z_{m 2} & \cdots & z_{m n}
\end{array}\right]
$$

where $A_{1}$ to $A_{\mathrm{m}}$ are possible alternatives. In this study, 90 possible alternative solutions were considered. $z_{11}$ to $z_{\mathrm{mn}}$ represents the performance of the alternative $A_{1}$ to $A_{\mathrm{m}}$ with respect to the criteria $\mathrm{C}_{1}$ to $\mathrm{C}_{\mathrm{n}}$. Five criteria, $\eta_{\mathrm{bth}}, \mathrm{NO}_{\mathrm{x}}, \mathrm{HC}$, smoke and $\mathrm{CO}$, were considered.

Step 2: Calculation of a normalized DM matrix

The performance DM matrix values $\left(z_{11}\right.$ to $\left.z_{\mathrm{mn}}\right)$ were transformed into unitless values for comparisons across criteria. The normalization was done using equation (9).

$$
n_{i j}=\frac{z_{i j}}{\sqrt{\sum_{i=1}^{m} z_{i j}^{2}}}
$$

where $n_{\mathrm{ij}}$ is the normalized value.

Step 3: The computation of a weighted normalized DM matrix

The weighted normalized value can be estimated by using the mathematical statement given in equation (10).

$$
v_{i j}=w_{j} n_{i j}
$$

where $v_{\mathrm{ij}}$ is the weighted normalized value and $w_{\mathrm{j}}$ is the weightage value of individual responses. The sum of the weightage value of all the individual responses should be equivalent to 1 . There are several methods available to assess weighing factors such as the eigenvector method, which is used in AHP, linear programming for multi-dimensional analysis of preferences (LINMAP), the Simos method and the revised Simos method [35].

In this study, the weightage of all responses was calculated by using the Simos principle which is based on a 'card-playing' strategy in which different responses were segregated in various levels and then the ranking and weighting of the levels were done. In order to assign weights to responses, J. Simos proposed the following algorithm. 


\section{Grouping:}

$\eta_{\text {bth }}, \mathrm{NO}_{\mathrm{x}}$ emissions and smoke emissions were grouped as Group I and the remaining responses, $\mathrm{HC}$ emissions and $\mathrm{CO}$ emissions were grouped as Group II.

\section{Assigning a position:}

A position was assigned to each response based on low to high importance. Group II responses, $\mathrm{HC}$ emissions and $\mathrm{CO}$ emissions were placed under position 1 and position 2, respectively, whereas Group I responses, $\eta_{\mathrm{bth}}$, $\mathrm{NO}_{\mathrm{x}}$ emissions and smoke emissions were placed under position 3 to position 5 , respectively.

Determination of the non-normalized weight:

Non-normalized weights (average weights) were measured by dividing the sum of the positions in the corresponding group by the total sum of the positions as shown in Table 3.

\section{Determination of the normalized weight:}

Normalized weights (relative weights) were calculated for every response through dividing the non-normalized weight in a particular group by the number of responses in the corresponding group. So, the individual weightage of the responses in Group I was 0.267 and the weightage of the responses in Group II was 0.1 . Table 4 presents all values acquired from the Simos process.

Table 3 Simos results

\begin{tabular}{|c|c|c|c|c|}
\hline Group & Responses & Position & Non-normalized weight & Normalized weight \\
\hline I & $\begin{array}{c}\eta_{\text {bth }} \\
\text { NO } \\
\text { smoke }\end{array}$ & $3,4,5$ & 0.8 & 0.267 \\
\hline II & $\begin{array}{c}\mathrm{HC} \\
\mathrm{CO}\end{array}$ & 1,2 & 0.2 & 0.1 \\
\hline
\end{tabular}

Step 4: Calculation of $v_{\mathrm{j}}^{+}$and $v_{\mathrm{j}}^{-}$

$v_{\mathrm{j}}^{+}$increases the benefit criteria and decreases the cost criteria, whereas $v_{\mathrm{j}}^{-}$increases the cost criteria and reduces the benefit criteria. In Table $4, v_{\mathrm{j}}^{+}$and $v_{\mathrm{j}}^{-}$obtained from the TOPSIS method are presented.

Table 4 Values of $v_{j}^{+}$and $v_{j}^{-}$

\begin{tabular}{|c|c|c|c|c|c|}
\hline & $\eta_{\text {bth }}$ & $\mathrm{NO}_{\mathrm{x}}$ & $\mathrm{HC}$ & Smoke & $\mathrm{CO}$ \\
\hline$\left(\mathrm{v}_{\mathrm{j}}^{+}\right)$ & 0.02658 & 0.0021 & 0.00109 & 0.00015 & 0.00106 \\
\hline$\left(\mathrm{v}_{\mathrm{j}}^{-}\right)$ & 0 & 0.03248 & 0.01537 & 0.06985 & 0.01485 \\
\hline
\end{tabular}

Step 5. Measurement of the separation measures from $v_{\mathrm{j}}^{+}$and $v_{\mathrm{j}}^{-}$

The separation of all alternative solutions from $v_{\mathrm{j}}^{+}$was calculated from equation (11)

$$
d_{i}^{+}=\sqrt{\sum_{j=1}^{n}\left(v_{i j}-v_{j}^{+}\right)^{2}}
$$

The separation of all alternative solutions from $v_{\mathrm{j}}^{-}$was calculated from equation (12)

$$
d_{i}^{-}=\sqrt{\sum_{j=1}^{n}\left(v_{i j}-v_{j}^{-}\right)^{2}}
$$

Step 6: Computation of the relative closeness $\left(R_{\mathrm{i}}\right)$ to $v_{\mathrm{j}}^{+}$

$R_{\mathrm{i}}$ to $v_{\mathrm{j}}^{+}$was calculated from the following equation (13):

$$
R_{i}=\frac{d_{i}^{-}}{d_{i}^{-}+d_{i}^{+}}
$$

$R_{\mathrm{i}}$ to $v_{\mathrm{j}}{ }^{+}$is between 0 and 1 . 
Experimental Investigation, ANN Modelling and TOPSIS Optimization of a Gasoline Premixed HCCI-DI Engine

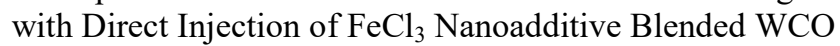

Step 7: Ranking of the preference order

The ranking of the preference order was done by arranging $R_{\mathrm{i}}$ values in descending order. The maximum value of $R_{\mathrm{i}}$ indicates the best option among all alternative solutions. In this study, the $\mathrm{FeCl}_{3}$ nanoadditive blend fuelled DI combustion engine at $25 \%$ load secured the first rank with the relative closeness value of 0.83493 .

\section{Conclusion}

The HCCI-DI engine was investigated through an experimental analysis in which gasoline as the premixed fuel and the $\mathrm{FeCl}_{3}$ nanoadditive blended WCO as the DI fuel were used. The output parameters of the HCCI-DI engine were compared with the diesel fuelled DI engine. An ANN model was proposed to predict the performance and emission tendency. Further, the TOPSIS optimization technique was incorporated to optimize the input parameters for high $\eta_{\text {bth }}$ and low exhaust emissions. The following conclusions have been made:

1. Direct injection of WCO caused a reduction in the $p_{\max }$ values of up to $2.17 \%$ compared to diesel. The $\mathrm{FeCl}_{3}$ nanoadditive blended fuel caused an increase in the $p_{\max }$ values. Further, an increase in the $p_{\max }$ values was observed in the HCCI-DI combustion.

2. HCCI-DI combustion significantly increased $\eta_{\mathrm{bth}}$ of the engine. Further increase in $\eta_{\text {bth }}$ was observed when the $\mathrm{FeCl}_{3}$ nanoadditive blended fuel was used.

3. The gasoline premixed HCCI-DI combustion produced $4.3 \%$ less $\mathrm{NO}_{\mathrm{x}}$ emissions compared with the DI combustion.

4. $54.17 \%$ and $22.69 \%$ decrease in $\mathrm{HC}$ and smoke emissions, respectively, were observed in the case of the WCO fuelled combustion compared with the diesel fuelled combustion.

5. An ANN model was prepared and validated by using $R$ and $R^{2}$ values. The $R$ value ranged from 0.999718 to 0.999737 , while the $R^{2}$ value ranged from 0.999436 to 0.99831. Based on the results, it was found that the suggested ANN model can be used for forecasting engine parameters with sufficient accuracy.

6. The TOPSIS optimization technique was incorporated to determine the optimum engine running conditions. Based on the relative closeness value, the $\mathrm{FeCl}_{3}$ nanoadditive blended DI combustion at low load was found as the optimum solution.

\section{REFERENCES:}

[1] S. Bhandarkar, "Vehicular Pollution, Their Effect on Human Heatlh and Mitigation Measures," Veh. Eng., vol. 1, no. 2, pp. 33-40, 2013.

[2] P. M. Yang, C. C. Wang, Y. C. Lin, S. R. Jhang, L. J. Lin, and Y. C. Lin, "Development of novel alternative biodiesel fuels for reducing PM emissions and PM-related genotoxicity," Environ. Res., vol. 156, pp. 512-518, 2017. https://doi.org/10.1016/j.envres.2017.03.045

[3] M. G. Kulkarni and A. K. Dalai, "Waste cooking oil - an economic source for biodiesel: a review," Ind. Eng. Chem. Res., vol. 45, pp. 2901-2913, 2006. https://doi.org/10.1021/ie0510526

[4] K. Muralidharan and D. Vasudevan, "Performance, emission and combustion characteristics of a variable compression ratio engine using methyl esters of waste cooking oil and diesel blends," Appl. Energy, vol. 88, no. 11, pp. 3959-3968, 2011. https://doi.org/10.1016/j.apenergy.2011.04.014

[5] C. C. Enweremadu and H. L. Rutto, "Combustion, emission and engine performance characteristics of used cooking oil biodiesel - A review," Renewable and Sustainable Energy Reviews, vol. 14, no. 9. pp. 2863-2873, 2010. https://doi.org/10.1016/j.rser.2010.07.036

[6] Y. C. Chang et al., "Effects of waste cooking oil-based biodiesel on the toxic organic pollutant emissions from a diesel engine," Appl. Energy, vol. 113, no. 840, pp. 613-638, 2014.

https://doi.org/10.1016/j.apenergy.2013.08.005 
Experimental Investigation, ANN Modelling and TOPSIS Optimization of a Gasoline Premixed HCCI-DI Engine

with Direct Injection of $\mathrm{FeCl}_{3}$ Nanoadditive Blended WCO

[7] S. Onishi, S. H. Jo, K. Shoda, P. Do Jo, and S. Kato, "Active Thermo-Atmosphere Combustion (ATAC) A New Combustion Process for Internal Combustion Engines,” SAE Tech. Pap., pp. 0-12, 1979. https://doi.org/10.4271/790501

[8] M. Christensen, B. Johansson, P. Amnéus, and F. Mauss, "Supercharged Homogeneous Charge Compression Ignition," in SAE Technical Papers, 1998, no. 724. https://doi.org/10.4271/980787

[9] R. K. Maurya and A. K. Agarwal, "Experimental study of combustion and emission characteristics of ethanol fuelled port injected homogeneous charge compression ignition (HCCI) combustion engine," Appl. Energy, vol. 88, no. 4, pp. 1169-1180, 2011. https://doi.org/10.1016/j.apenergy.2010.09.015

[10] S. Srihari and S. Thirumalini, "Investigation on reduction of emission in PCCI-DI engine with biofuel blends," Renew. Energy, vol. 114, pp. 1232-1237, 2017. https://doi.org/10.1016/j.renene.2017.08.008

[11] G. Coskun, H. S. Soyhan, U. Demir, A. Turkcan, A. N. Ozsezen, and M. Canakci, "Influences of second injection variations on combustion and emissions of an HCCI-DI engine: Experiments and CFD modelling," Fuel, vol. 136, pp. 287-294, 2014. https://doi.org/10.1016/j.fuel.2014.07.042

[12] H. Venu and V. Madhavan, "Effect of Al2O3nanoparticles in biodiesel-diesel-ethanol blends at various injection strategies: Performance, combustion and emission characteristics," Fuel, vol. 186, pp. 176-189, 2016. https://doi.org/10.1016/j.fuel.2016.08.046

[13] H. Kumar Patel and S. Kumar, "Experimental analysis on performance of diesel engine using mixture of diesel and bio-diesel as a working fuel with aluminum oxide nanoparticle additive," Therm. Sci. Eng. Prog., vol. 4, no. x, pp. 252-258, 2017. https://doi.org/10.1016/j.tsep.2017.09.011

[14] S. P. Jena, S. K. Acharya, H. C. Das, P. P. Patnaik, and S. Bajpai, "Investigation of the effect of $\mathrm{FeCl} 3$ on combustion and emission of diesel engine with thermal barrier coating," Sustain. Environ. Res., pp. 1-7, 2017. https://doi.org/10.1016/j.serj.2017.10.002

[15] K. Nanthagopal, B. Ashok, A. Tamilarasu, A. Johny, and A. Mohan, "Influence on the effect of zinc oxide and titanium dioxide nanoparticles as an additive with Calophyllum inophyllum methyl ester in a CI engine," Energy Convers. Manag., vol. 146, pp. 8-19, 2017. https://doi.org/10.1016/j.enconman.2017.05.021

[16] B. Ashok, K. Nanthagopal, R. Subbarao, A. Johny, A. Mohan, and A. Tamilarasu, "Experimental studies on the effect of metal oxide and antioxidant additives with Calophyllum Inophyllum Methyl ester in compression ignition engine," J. Clean. Prod., vol. 166, pp. 474-484, 2017. https://doi.org/10.1016/j.jclepro.2017.08.050

[17] A. Chakraborty, S. Roy, and R. Banerjee, "An experimental based ANN approach in mapping performance-emission characteristics of a diesel engine operating in dual-fuel mode with LPG," J. Nat. Gas Sci. Eng., vol. 28, pp. 15-30, 2016. https://doi.org/10.1016/j.jngse.2015.11.024

[18] H. Taghavifar, A. Mardani, A. Mohebbi, and H. Taghavifar, "Investigating the effect of combustion properties on the accumulated heat release of di engines at rated EGR levels using the ANN approach," Fuel, vol. 137, pp. 1-10, 2014. https://doi.org/10.1016/j.fuel.2014.07.073

[19] S. Javed, Y. V. V Satyanaray ana Murthy, R. U. Baig, and D. Prasada Rao, "Development of ANN model for prediction of performance and emission characteristics of hydrogen dual fueled diesel engine with Jatropha Methyl Ester biodiesel blends," J. Nat. Gas Sci. Eng., vol. 26, pp. 549-557, 2015. https://doi.org/10.1016/j.jngse.2015.06.041

[20] J. J. Wang, Y. Y. Jing, C. F. Zhang, and J. H. Zhao, "Review on multi-criteria decision analysis aid in sustainable energy decision-making," Renewable and Sustainable Energy Reviews. 2009. https://doi.org/10.1016/j.rser.2009.06.021

[21] B. Gurunathan and A. Ravi, "Biodiesel production from waste cooking oil using copper doped zinc oxide nanocomposite as heterogeneous catalyst," Bioresour. Technol., vol. 188, pp. 124-127, 2015. https://doi.org/10.1016/j.biortech.2015.01.012

[22] E. Buyukkaya, "Effects of biodiesel on a di diesel engine performance, emission and combustion characteristics," Fuel, vol. 89, no. 10, pp. 3099-3105, 2010. https://doi.org/10.1016/j.fuel.2010.05.034

[23] M. A. Ismael, M. R. Heikal, A. Rashid, A. Aziz, and C. Crua, "An overview of experimental techniques of the investigation of water-diesel emulsion characteristics droplets micro-explosion," ARPN J. Eng. Appl. Sci., vol. 11, no. 20, pp. 11975-11981, 2016.

[24] A. Jamrozik, W. Tutak, M. Pyrc, and M. Sobiepański, "Experimental investigations on combustion, performance, and emission characteristics of stationary CI engine fueled with diesel-methanol and biodiesel-methanol blends," Environ. Prog. Sustain. Energy, vol. 36, no. 4, pp. 1151-1163, 2017. https://doi.org/10.1002/ep.12541 
[25] S. Vedharaj et al., "Reduction of harmful emissions from a diesel engine fueled by kapok methyl ester using combined coating and SNCR technology," Energy Convers. Manag., 2014. https://doi.org/10.1016/j.enconman.2013.12.056

[26] G. M. Lionus Leo, S. Sekar, and S. Arivazhagan, "Experimental investigation, optimization and ANN model prediction of a gasoline premixed waste cooking oil fueled HCCI-DI engine," J. Brazilian Soc. Mech. Sci. Eng., vol. 40, no. 2, p. 49, 2018. https://doi.org/10.1007/s40430-018-0967-1

[27] P. Das, P. M. V. Subbarao, and J. P. Subrahmanyam, "Control of combustion process in an HCCI-DI combustion engine using dual injection strategy with EGR,” Fuel, vol. 159, pp. 580-589, 2015. https://doi.org/10.1016/j.fuel.2015.07.009

[28] M. Fathi, R. Khoshbakhti Saray, and M. David Checkel, "Detailed approach for apparent heat release analysis in HCCI engines," Fuel, vol. 89, no. 9, pp. 2323-2330, 2010. https://doi.org/10.1016/j.fuel.2010.04.030

[29] P. P. Patnaik, S. P. Jena, S. K. Acharya, and H. C. Das, "Effect of FeCl3and diethyl ether as additives on compression ignition engine emissions," Sustain. Environ. Res., 2017. https://doi.org/10.1016/j.serj.2017.01.002

[30] G. R. Kannan, K. R. Balasubramanian, S. P. Sivapirakasam, and R. Anand, "Studies on biodiesel production and its effect on di diesel engine performance, emission and combustion characteristics," Int. J. Ambient Energy, vol. 32, no. 4, pp. 179-193, 2011. https://doi.org/10.1080/01430750.2011.625722

[31] M. F. Othman, A. Adam, G. Najafi, and R. Mamat, "Green fuel as alternative fuel for diesel engine: A review," Renewable and Sustainable Energy Reviews, vol. 80. pp. 694-709, 2017. https://doi.org/10.1016/j.rser.2017.05.140

[32] B. Ashok, K. Nanthagopal, and D. Sakthi Vignesh, "Calophyllum inophyllum methyl ester biodiesel blend as an alternate fuel for diesel engine applications," Alexandria Engineering Journal, 2016. https://doi.org/10.1016/j.aej.2017.03.042

[33] Y. Zhao, Y. Wang, D. Li, X. Lei, and S. Liu, "Combustion and emission characteristics of a DME (dimethyl ether)-diesel dual fuel premixed charge compression ignition engine with EGR (exhaust gas recirculation)," Energy, vol. 72, no. x, pp. 608-617, 2014. https://doi.org/10.1016/j.energy.2014.05.086

[34] M. Jeftić, S. Yu, X. Han, G. T. Reader, M. Wang, and M. Zheng, "Effects of postinjection application with late partially premixed combustion on power production and diesel exhaust gas conditioning," $J$. Combust., vol. 2011, 2011. https://doi.org/10.1155/2011/891096

[35] A. Shanian, A. S. Milani, C. Carson, and R. C. Abeyaratne, "A new application of ELECTRE III and revised Simos' procedure for group material selection under weighting uncertainty," Knowledge-Based Syst., 2008. https://doi.org/10.1016/j.knosys.2008.03.028

Submitted: $\quad 02.12 .2018$

Accepted: $\quad$ 28.5.2019
Assist.Prof. Lionus Leo G M

Prof. Arivazhagan Sundaraganesan

Department of Mechanical Engineering

St. Joseph's College of Engineering Chennai-600119, India

Prof. Sekar Subramani

Department of Mechanical Engineering

Rajalakshmi Engineering College

Chennai-602105, India 